\title{
САМОБЫТНОСТЬ ТРАНСЦЕНДЕНТАЛЬНЫХ ТЕОРИЙ СОЦИАЛЬНОГО ДЕЙСТВИЯ
}

\section{THE ORIGINALITY OF TRANSCENDENTAL THEORIES SOCIAL ACTION}

\section{Nasirov}

Summary: This article examines the specifics of understanding the fundamental concept in transcendentalism, as well as in other paradigms, it leaves a significant imprint on the consideration of the behavior of an individual. At the same time, within the transcendental tradition itself, the understanding of the fundamental concept - the universal structures of consciousness - is not integral, but breaks up into various currents. For example, in contrast to the representatives of Baden neo-Kantianism, who considered transcendental structures mainly in a psychological, rather than value, key. For the study of social action, such an approach directly indicated that in the first case, the interest of scientific knowledge is aimed at finding causes, and in the second, at establishing the norms of an act. Therefore, the conceptual idea of the psychological direction is defined as voluntary, and Baden neo-Kantianism - as rational and normative. Also, for the axiological current in Kantianism, as well as for the psychological one, the reduction of social behavior is characteristic, firstly, to morality, and secondly, to individual action.

Keywords: transcendental theory, paradigm, social action, emotional reaction, existential experience, axiological approach.

\author{
Насиров Марат Нухбалаевич \\ К.фр.н., дочент, Нижегородская академии МВД России, \\ 2. Нижний Новгород \\ marat.nn@bk.ru
}

Аннотация: В настоящей статье рассматривается специфика понимания фундаментального концепта в трансцендентализме, так же, как и в других парадигмах, он накладывает существенный отпечаток на рассмотрение поведения индивида. При этом внутри самой трансцендентальной традиции понимание фундаментального концепта - общечеловеческих структур сознания - не является целостным, а распадается на различные течения. Например, в отличие от представителей баденского неокантианства, которые рассматривали трансцендентальные структуры преимущественно в психологическом, а не ценностном ключе. Для исследования социального действия такой подход прямо указывал на то, что в первом случае интерес научного познания направлен на поиск причин, а во втором - на установление норм поступка. Поэтому концептуальная идея психологического направления определяется как волюнтарная, а баденского неокантианства - как рационально-нормативная. Также, для аксиологического течения в кантианстве, как и для психологического, характерна редукция социального поведения, во-первых, к нравственности, а во-вторых, к индивидуальному действию.

Ключевые слова: трансцендентальная теория, отношения парадигма, составляют социальное реакции действие, способаэмоциональная разрешении реакция, аксиологических экзистенциальное домочадцам переживание идеального, аксиологический означает подход потому.
$\Pi$ редставление о самобытности фундаментального концепта в различных толкованиях трансцендентальной парадигмы может накладывать немаловажный отпечаток на специфический характер и структуру социального действия. Исследуя зависимость понимания социального действия от трактовки фундаментального концепта в интерпретациях трех основных трансцендентальных парадигм, например таких как неокантианская, феноменологическая и символо-интеракционистская, в первой из них в наиболее ярком виде прослеживается зависимость их понимания. Поэтому, наличие в кантианской традиции различных направлений, образы фундаментального концепта - трансцендентального сознания, разрабатываемого в ней, - существенным образом отличаются друг от друга.

Таким образом, в кантианской традиции появляются два главных направления, которые в свою очередь оказали прямое воздействие на формирование теорий социального действия. Первое направление, зависит от эмпирического метода и напрямую связано с интересом к внутренним переживаниям индивида, поэтому может быть названо психологическим. Поэтому, в объяснении связи между трансцендентальным началом и социальным поведением индивида, мыслители Гербарт и Вундт обращались к понятию души. Второе направление, было предложено баденской школой неокантианства и развило ценностное понимание трансцендентальных структур, которое в полной мере раскрыло их влияние на индивида и по праву может быть названо аксиологическим. Рассмотрим специфику решения проблемы универсального и индивидуального сознания в указанных течениях кантианской традиции. У Гербарта трансцендентальное начало предстает в виде сферы представлений, понятий и переживаний, находясь в которой человек осуществляет познание единой самотождественной реальности. Поэтому посредством познания, мир предстает в виде множественного бытия. Однако, человек в процессе познания раскрывает не саму реальность, а лишь ее видимость, а природно-социальный мир порождается универсальным, общечеловеческим сознанием, к которому принадлежит каждый человек.

Центром этой трансцендентальной сферы является Я, которое лишено самотождественности и признается Гербартом временным соединением понятий, представ- 
лений и переживаний. Таким образом, трансцендентальное начало существует не вне индивида, но в нем самом. Отличие же эмпирического от трансцендентального заключается в том, что первое ограничено рамками индивидуального, тогда как второе охватывает всю совокупность возможного опыта. Поэтому трансцендентальное следует рассматривать как необходимую предпосылку психики, реализующуюся в самой психике. Сущность психической жизни немецкий философ видит в стремлении индивида к самосохранению. При этом представления рассматриваются как важнейшая составляющая сознания, возникающая как реакция на внешнее раздражение, указывающая на подлинную или мнимую угрозу.

Самосохранение как важнейшая психическая установка лежит в основе нравственности, основные идеи которой - «свобода», «совершенство», «доброжелательность», «право», «справедливость» - позволяют человеку оценивать пользу или вред того или иного поступка для чужой или собственной индивидуальности. Нравственность, представляя собой внутреннее пространство индивида, переносится во вне и служит основанием социальной жизни. В своей «Истории новой философии» В. Виндельбанд следующим образом раскрывает фундаментальный характер нравственности по отношению к социальным отношениям. «К пяти первоначальным идеям примыкает... ряд производных, ....которые ... содержат в себе совокупность нравственных «благ». Гербарт относит к ним... систему возмездия, правовое общество, систему управления и систему культуры, причем эти четыре учреждения объединяются в органическое единство в виде одушевленного общества. Таким образом, этика переходит в социальную философию, и Гербарт строит понятие государства как процесса жизни человечества, в котором потеряют развитие все эти блага. Но и в государстве он опять видит по преимуществу социальный механизм: государство и для него - «человек в большем виде». Составляющие его элементы - люди, обладающие волей. Учение о государстве является скорее статикой и механикой социальных сил, нежели философско-правовым построением, а политика есть вычисление психолого-социальных необходимостей» [2, с. 418-419].

Выстраивая стройную систему трансцендентального начала, включающую в себя логический, психологический, эмпирический, социальный, правовой и политический уровни, Гербарт не склонен рассматривать индивида в качестве заложника идеальных структур. Напротив, структуры и лежащие в их основании трансцендентальные способности, формируются в опыте в результате непрерывной упорядочивающей работы индивида над возникающими в процессе взаимодействия с реальностью понятиями, представлениями и переживаниями. Поэтому, не будучи внутренне единым, индивид, тем не менее, является подлинным субъектом психического, нравственного и социального действия. Весь окружаю- щий индивида социальный мир есть результат проекции его воли и воли подобных ему существ, а знание об этом мире возникает как итог выбора им определенного способа разрешения познавательных проблем. Таким образом, деятельность индивида, а не надындивидуального начала, служит формирующей силой как социальной реальности, так и социального познания. Поэтому критическая метафизика И.Ф. Гербарта, несмотря на признание его независимой от сознания реальности, служит ярким примером трансцендентальной философии.

Для парадигмального метода концепция Гербарта интересна тем, что на ее примере можно проследить решение трех важнейших проблем, связанных с исследованием феномена парадигмальности социального познания. Первая из них направлена на раскрытие влияния фундаментального концепта той или иной парадигмы на изучаемый предмет. В философии Гербарта четко видно, что явное сближение трансцендентального начала с психикой приводит к волюнтаристской интерпретации социального действия. При этом необходимо подчеркнуть, что волюнтаризм в данном случае не означает возврат к натурализму, поскольку в данном случае воля выступает как идеальное начало, гарантируя индивиду, как это принято в кантовской традиции, свободу от природного влечения. Зависимость же предмета исследования от фундаментального концепта означает, что чисто эмпирическое исследование какого-либо феномена вне различного рода идеальных конструкций невозможно, а потому специально-научное познание нуждается в познании философском. Сам Гербарт при всем его увлечении опытом и эмпирическими науками вполне отдавал себе отчет и по этой причине придерживался точки зрения Канта, согласно которой философия должна играть роль методологии научного познания. Данная точка зрения вполне разделяется и методом парадигмального анализа.

Здесь возникает переход ко второй проблеме рассматриваемого метода, связанной с решением вопроса о парадигмальности социального познания. В системе Гербарта эта проблема решается путем указания на зависимость социальных отношений от нравственности. Немецкий мыслитель признает социальное познание не только зависимым от другого вида познавательной деятельности, но и четко указывает этот источник. Подобно тому, как социальные отношения представляют собой иституализацию нравственных отношений, социальное познание базируется на элементарных идеях, обнаруживаемых моральным сознанием. Для понимания характера социального действия это означает отрицание его автономного статуса. В данном вопросе Гербарт также не оригинален, поскольку следует за Кантом, рассматривавшим мораль в качестве нормы для социального поведения.

Третья проблема, с которой сталкивается примене- 
ние парадигмального метода, заключается в выявлении полноты реализации структуры парадигмы в конкретной системе, теории или учении. В парадигме социального познания можно выделить четыре основных уровня: фундаментальный концепт, концептуальную идею, концептуальную модель и теорию. Эта структура позволяет выявить степень философской отрефлексированности оснований того или иного исследования, а также глубину проработки эмпирического материала, осуществленной в нем. Другими словами, установление полноты содержания парадигмы социального познания в конкретном исследовании дает основание судить о степени инструментализации философской идеи, лежащей в его теоретической базе. Рассмотрение системы Гербарта на предмет включенности его концепции социального действия в контекст онтологических, гносеологических, ценностных и социально-философских категорий позволяет сделать вывод о том, что в ней осуществлена глубокая разработка фундаментального концепта и концептуальной идеи, но практически полностью отсутствует идеальная модель изучаемого феномена и его развернутая теория.

Логическое продолжение психологической интерпретации трансцендентализма можно обнаружить в творчестве немецкого психолога и мыслителя В. Вундта. Раскрывая черты сходства и различия между учениями Вундта и Гербарта, отечественная исследовательница Т.А. Акиндинова обращает внимание на тяготение первого к детальному изучению эмпирического материала: «В. Вундт, возглавив во второй половине XIX в. экспериментальное изучение человеческой психики, тем не менее, посчитал методологию Гербарта недостаточной для понимания высших психических процессов - мышления, речи и т. п. - и сам попытался исследовать психику в ее историко-культурной обусловленности. В его десятитомной «Психологии народов» содержится обширнейшее описание языка, мифологии, обычаев многих народов мира. Для характеристики целостности сознания каждого из них Вундт использует гегелевское понятие «народный дух» и рассматривает культуру как его выражение. Сохраняя, однако, принципиальную установку на описание без «метафизических пережитков» и не претендуя на установление каких-либо общих законов психической жизни, Вундт был далек от попыток собственно философского осмысления культурологических проблем: его «Психология народов» имеет право называться, скорее, «социологией обыденного сознания»» [1, с. 95].

Как следует из вышесказанного, Вундт конкретизирует идею Гербарта об определяющей для социального поведения роли психики и придает ей форму концептуальной модели, получившей наименование «народного духа». Данная модель позволила не только рассматривать поведение индивида как обусловленное нравственным началом, но и представить само нравственное начало не в теоретическом, а в историческом плане. Благодаря этому, индивид предстает в контексте социаль- ной и культурной общности, к которой он принадлежит. Эта общность, как и любая другая форма, несмотря на свою историческую принадлежность, всегда содержит в себе устойчивые идеальные моменты, позволяющие отличить ее от любой другой общности. Именно поэтому Вундт, вслед за Гегелем, видит в социальных действиях индивида нечто большее, чем сиюминутные реакции на сложившуюся ситуацию. Этот идеальный пласт, стоящий за спиной индивида и, вместе с тем, индивидом формируемый и поддерживаемый, немецкий психолог и называет «народным духом».

Следует подчеркнуть, что данное понятие, играющее роль концептуальной модели в восприятии эмпирического материала, оказалось весьма плодотворным для кантианской традиции. Под различными наименованиями оно использовалось многими социологами-неокантианцами, тяготеющими как к психологической, так и к аксиологической интерпретации фундаментального концепта трансцендентальной парадигмы. В частности, его достаточно плодотворно применял Л.И. Петражицкий, у которого оно выступает под именем «народная психика». Но в отличие от Вундта, оно нацелено не на оформление эмпирических фактов, но на выявление культурно-исторической специфики социальных норм, определяющих поведение индивидов. Несмотря на это различие, понятие «народная психика», так как и понятие «народный дух», играет роль концептуальной модели, служащей базой для теоретической и эмпирической методологии социального исследования. Различие же между характером психологических и аксиологических теорий социального действия заключается в том, что перевес в первом случае отдается научному наблюдению и изменению, а во втором - нормативным методам.

Основание данного различия следует искать в специфике интерпретации фундаментального концепта двух течений кантианской традиции. В отличие от Вундта и Гербарта, представители баденского неокантианства В. Виндельбанд, Г. Риккерт, а также большинство русских неокантианцев-социологов и правоведов рассматривали трансцендентальные структуры преимущественно в ценностном, а не психологическом ключе. Для исследования социального действия это означало смещение научного интереса от поиска причин к установлению норм поступка. Поэтому концептуальную идею баденского неокантианства по отношению к анализу социального действия можно определить как рационально-нормативную. Она заключается в том, что социальному познанию необходимо раскрыть ценностные предпочтения и связанные с ними нормативные требования, которыми руководствуется индивид в различных видах своей деятельности.

Комментируя специфику понимания долженствования и определяя его место среди других способностей индивида в философии В. Виндельбанда, Т.А. Акиндино- 
ва пишет: «Вынесение оценок оказывается возможным, поскольку субъект является одновременно и носителем практического разума - единого идеального мира ценностей, обладающего характером долженствования... Долженствование, или что-то же самое, «притязание на обще значимость», выделяет, согласно Виндельбанду, из всего многообразия оценок три их вида: логические, этические и эстетические. Только в них выражается не просто наше индивидуальное чувство удовольствия или неудовольствия от представляемого предмета, а норма оценки, или правильность появления чувства удовольствия или неудовольствия в суждении о ценности... Сфера же влияния... мира ценностей на эмпирический мир и образует культуру» [4, с. 100].

Для аксиологического течения, так же как и для психологического, в кантианстве характерна редукция социального поведения, во-первых, к нравственности, а во-вторых, к индивидуальному действию. Но если психологическое направление ставило нравственность в зависимость от волевого акта, то аксиологическое - отстаивало рационалистический образ морального сознания. Соответственно этому и индивид в первом случае выступает, прежде всего, как живое существо, а во втором - как метафизический субъект, как личность. Последняя предстает как вневременное духовное явление, как идеал, к которому должен стремиться каждый человек. В свою очередь, общество, являясь результатом действий индивидов, стремящихся стать личностями, также рассматривается в неокантианстве как идеальный конструкт, который не может найти в историческом процессе полного воплощения.

В наиболее ярком виде трансцендентальнаая рационально-нормативная идея социальной реальности выражена в творчестве П.И. Новгородцева. Раскрывая место личности и характер ее действий в рамках этой идеи, Г.Е. Зборовский обращает внимание на следующие моменты концепции Новгородцева. «По его мнению, человеческое общество отличается от мира живой природы, прежде всего, тем, что в нем существуют нормы как первоначальные задатки всеобщего долженствования. Эти нормы составляют нравственную основу структуры личности, поскольку человек живет именно по ним. Раз мы с этим согласны, то должны признать, что нормы являются основой также общества и культуры... Новгородцев не отождествлял общество и культуру, ... выступал против такого отождествления... Нравственность, по Новгородцеву, - это внутренняя для человека абсолютная ценность. Она позволяет личности быть не пассивным продуктом социальной среды, а единственным и основным источником сознательных решений и активных действий. Поэтому общество есть не что иное, как совокупность сознаний и действий отдельных людей» [3, с. 288].

Рассмотрение сознания в качестве идеального, а не природного феномена является характерной чертой всех направлений трансцендентализма. Данная методологическая установка свойственна и феноменологии, близкой по духу неокантианству. Но в отличие от неокантианства, феноменология имеет не рассудочный, а интуитивный характер. Вместе с тем, интеллектуальная интуиция в школе Э. Гуссерля не имеет спекулятивной природы, как это имело место в школе И.Г. Фихте и Г.Ф.В. Гегеля. Соответственно этому трансцендентальное в феноменологии выступает не в качестве априорной структуры человеческого сознания, формирующей реальность, а скорее как идеальный срез сознания, обнаруживаемый индивидом в акте интроспекции. Поэтому трансцендентальное в феноменологии предстает, в первую очередь, не в виде всеобщего и необходимого, как у Канта, но, прежде всего, в виде самоочевидного начала. Его самоочевидность может принимать как чисто смысловые, так и чувственно-наглядные формы. Анализ смысловых форм позволяет обнаружить базовые категории различных областей знания, тогда как анализ чувственно-данного устанавливает первичные способы данности предметов повседневной жизни. Самоочевидность смысловой и чувственной сфер познания имеет универсальный характер, она позволяет каждому индивиду обращаться к исследованию какого-либо идеального или чувственного предмета, процесса или явления. Соблюдение правил созерцания позволяет, вне зависимости от субъекта, получать одни и те же данные. Это означает, что самоочевидность имеет не только субъективный, но и интерсубъективный характер.

Для исследования социального феноменологическое учение о методах описания различных видов опыта и их изначальном интерсубъективном статусе имеет большое значение. В первую очередь, оно связано с возможностью создания особой концептуальной идеи, которая предлагает новый способ восприятия социальных действий. Эта идея, которую можно назвать концепцией интерсубъективности, конкретизируется в концептуальной модели, позволяющей исследовать такие важнейшие явления, как социализация и социальная реабилитация индивидов. В свою очередь, применение концептуальной модели к указанным явлениям приводит к возникновению различных феноменологических теорий социального действия. Например, проблема социализации у различных представителей феноменологической социологии и психологии осуществляется поразному.

Нам представляется возможным рассмотреть все основные уровни феноменологической интерпретации трансцендентальной парадигмы применительно к анализу социального действия на примере творчества одного ученого - австро-американского исследователя А. Щюца.

Проблемы, связанные с рассмотрением фундаментального концепта феноменологической интерпретации 
трансцендентальной парадигмы, затрагиваются А. Щюцем при разрешении вопроса определения характера социальных явлений в целом и социального действия в частности. Согласно точке зрения австрийского социолога, социальное не принадлежит к явлениям природного порядка, поскольку, в отличие от них, оно изначально наделено смыслом, доступным человеческому сознанию, т. е. внутренним смыслом. Поэтому «жизненный мир» - это не природа, а сфера человеческих отношений, в которой и осуществляются социальные действия. По отношению к теоретическому познанию «жизненный мир» обладает первичностью, поскольку идеальные конструкты, т. е. научные понятия, отталкиваются от повседневных явлений. Это означает, что научные концепции социального действия должны проходить проверку на соответствие непосредственной данности исследуемого феномена сознанию.

Концептуальная идея феноменологического исследования социального действия формируется Щюцем при перенесении понятия интерсубъективности из области гносеологии в область социального познания. В социальном мире интерсубъективность присутствует, согласно мнению австрийского ученого, в виде так называемого «здравого смысла», который представляет собой результат осмысления индивидами различных форм коммуникации. Характер «здравого смысла» при переходе от одной социальной группы к другой может существенным образом меняться. Эта динамика социального знания в наиболее явном виде предстает в процессах социализации и социальной реабилитации индивида.

Общим для теорий социализации и социальной реабилитации, разработанных Щюцем, является использование коммуникативной модели поведения человека. Важнейшим условием коммуникации служит общность пространства и времени, в которых находятся индивиды. Именно благодаря пространственной и временной общности индивидов формируется единый для той или иной группы взгляд на мир. Поэтому в процессе межличностного общения необходимо учитывать не столько индивидуальные, сколько типовые особенности человека. Так, для процесса общения важна группа, от лица которой в конкретной ситуации выступает индивид. Например, он может играть роли продавца или покупателя, начальника или подчиненного. Только благодаря знанию социальных ролей индивид может нормально существовать в обществе.

Коммуникативная модель социального действия находит свою конкретизацию в теориях социализации и социальной реабилитации. В первой теории Щюцем рассматривается процесс усвоения индивидом знания и норм поведения, связанных с взаимодействием с другими группами. Вторая теория описывает, напротив, ситуацию возвращения индивида в свою социальную группу после длительного отсутствия.
В теории социализации коммуникативная модель является применимой, поскольку исследуемый Щюцем феномен предполагает понимание представителями разных социальных групп черт сходства и различия, свойственных как собственному, так и чужому способу мышления и поведения. Так, успешная социализация предполагает: способность индивида придерживаться нужной точки зрения и воспринимать ситуацию соответствующим образом; умение усваивать язык различных социальных групп - «диалект повседневности»; понимание социального разграничения знания, наличие ступеней владения им и умение правильно использовать его в нужных ситуациях. Главным же в любом социальном действии является способность индивида правильно реконструировать мышление другого.

Теория социальной реабилитации Щюца изложена в его работе «Возвращающийся домой», в которой раскрываются трудности, возникающие в процессе коммуникации между индивидом и социальной группой, в которой он длительное время отсутствовал. Основанием применения коммуникативной модели в процессе создания теории социальной реабилитации служит характерное для западноевропейской философии и науки представление об индивиде как самодостаточном субъекте. Применительно к процессу адаптации индивида к изменившимся социальным условиям феноменологическая установка на конструирование другого сознания как составляющая социальной коммуникации - выглядит вполне уместной.

Для того чтобы облегчить адаптацию индивида, временно выпавшего из определенных социальных отношений, нужно, во-первых, фиксировать различия между его сознанием и сознанием представителей социальной группы, в которую он включается; во-вторых, сформировать в сознании обоих субъектов коммуникации определенные установки, способствующие правильному восприятию друг друга. Иллюстрацией первого момента служит различие между сознанием солдата и сознанием обывателя. Солдат - беспрекословно подчиняется приказам и не в состоянии изменить систему отношений, в которой находится. Обыватель - привык сам выбирать цели и средства их достижения.

Второй момент социальной реабилитации солдата, вернувшегося с войны, сам А. Щюц характеризует следующим образом: «Многое сделано, но еще большее предстоит сделать, чтобы подготовить возвращающегося домой ветерана к необходимости прилаживания к дому. Равно необходимо подготовить к его приходу и домашнюю группу. Через прессу и радио следует разъяснить домочадцам, что человек, которого они ждут, уже не тот, другой, и даже не такой, каким его воображают. Повернуть пропагандистскую машину в противоположном направлении, разрушить псевдотипы батальной жизни и жизни солдата вообще и заменить его на правду 
не простая задача» [5, с. 142].

Таким образом, анализируя природу и структуру социального действия в трансцендентальной парадигме, особое внимание следует уделить отношению индивида к социальной реальности в целом и конкретным отношениям, сложившимся в ней. Однако, подобного рода отношение может пониматься достаточно широко. Например, как эмоциональная реакция, экзистенциальное переживание или отнесение к ценности. Так или иначе, социальное действие в трансцендентализме, всегда будет наделено скрытым или явным смыслом, который нуждается в специфическом осмыслении. Одним из главных недостатков трансцендентального подхода к исследованию социального действия является тяготение к рассмотрению человека (индивида) в качестве замкнутой в себе монады. Подобного рода подход, с одной стороны, необратимо приведет впадением в солипсизм, а с другой - практически не соответствует социальной сущности человека.

\section{ЛИТЕРАТУРА}

1. Акиндинова Т.А. Философия культуры. Становление и развитие. - СПб.: Лань, 1998. - 448 с.

2. Виндельбанд В. История новой философии в ее связи с общей культурой и отдельными науками: в 2 т. / пер. с нем. - М.: ТЕРРА-Книжный клуб; КАНОНпресс-Ц, 2000.

3. Зборовский Г.Е. История социологии: учеб. - М.: Гардарики, 2004.

4. Самойлов С.Ф., Насиров М.Н. Методологические основания интегративной природы социального познания. Краснодар: Краснодарский университет МВД России, 2011. 158 с.

5. Ядов В.А. 0 диспозиционной регуляции социального поведения личности // Методологические проблемы социальной психологии. - М., 1975.

$\longrightarrow$ ○ Насиров Марат Нухбалаевич (marat.nn@bk.ru).

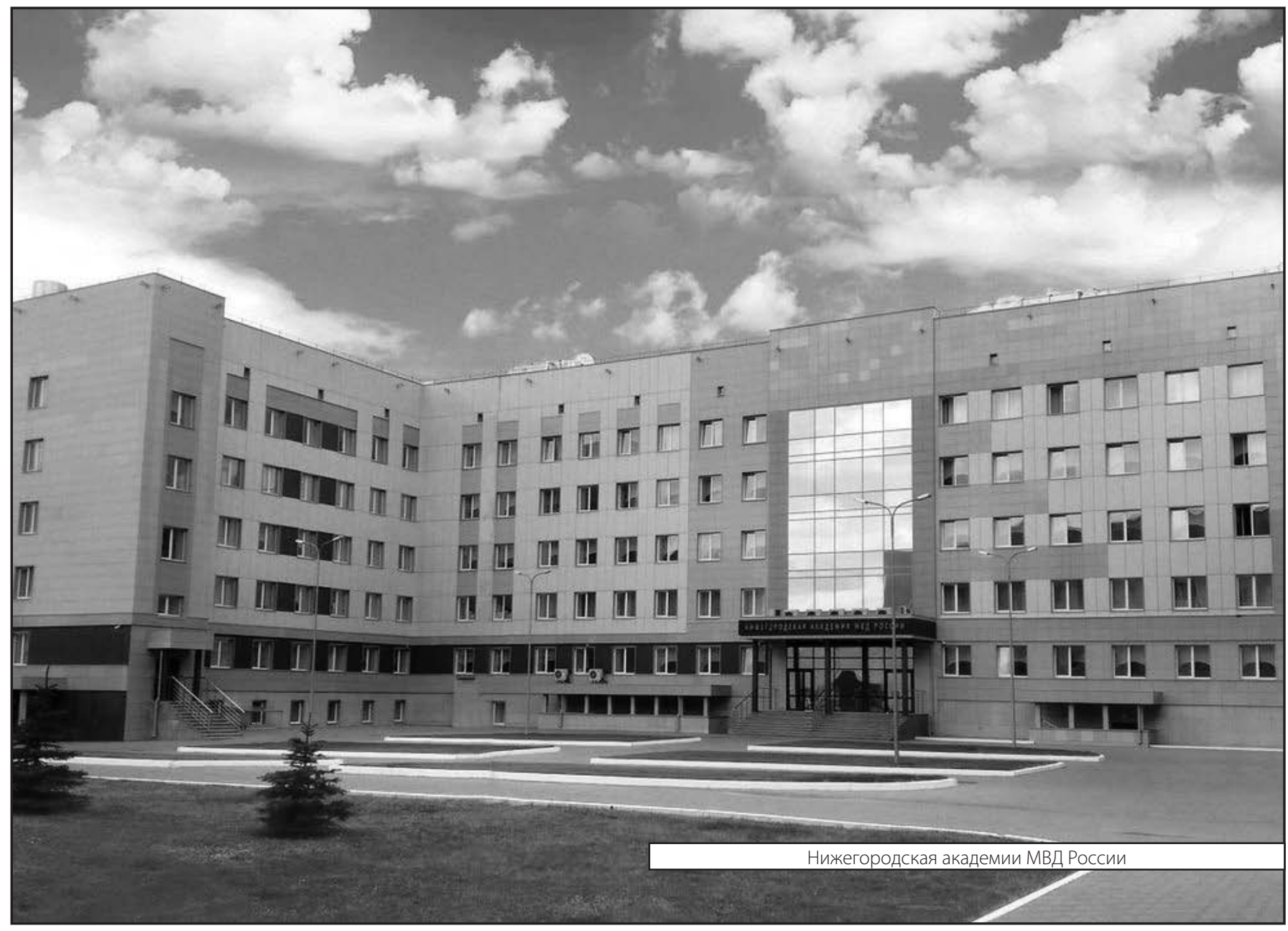

